\title{
HUB KEBUDAYAAN KOREA SELATAN DI JL. TAMAN KEMANG
}

\author{
Ramdha Rachmansyah ${ }^{1)}$, Andi Surya Kurnia ${ }^{2)}$ \\ 1)Program Studi S1 Arsitektur, Fakultas Teknik, Universitas Tarumanagara, rramdha@gmail.com \\ 2) Program Studi S1 Arsitektur, Fakultas Teknik, Universitas Tarumanagara, andik@ft.untar.ac.id
}

Masuk: 13-09-2020, revisi: 28-07-2020, diterima untuk diterbitkan: 24-09-2020

\begin{abstract}
Abstrak
Pemanfaatan isu global dalam bidang kebudayaan, memunculkan minat masyarakat untuk mencari tahu dan berkumpul di satu titik dimana kebudayaan yang sedang trend tersebut dapat diedukasikan. Isu global mengenai trend kebudayaan yang didapatkan dari hasil survey adalah Hallyu Wave, yaitu gelombang Kebudayaan Korea Selatan yang sedang berada di puncak pembicaraan masyarakat di dunia. Tujuan penelitian ini untuk mengetahui pola komunikasi yang dibangun oleh seluruh lapisan masyarakat dan untuk mengetahui proses integrasi sosial yang dilakukan. Pemilihan tapak dan pengolahan bangunan juga perlu memperhatikan keaslian arsitektural khas Korea Selatan, yang nantinya harus diadaptasikan pada lingkungan Indonesia yang diwadahkan pada sebuah hub. Hub ini dirancang pada metode perancangan kontekstual musical analogies dalam sisi arsitekturalnya, terutama dalam permainan tinggi-rendah dan maju-mundurnya bidang arsitektural, yang pada akhirnya akan memunculkan karakter integrasi kebudayaan Korea Selatan di Indonesia, khususnya di Jl. Taman Kemang, Kota Administrasi Jakarta Selatan, yang merupakan salah satu pusat $3^{\text {rd }}$ Place untuk Provinsi DKI Jakarta, dan beserta adaptasinya.
\end{abstract}

\section{Kata kunci: hub; kebudayaan; korea selatan; trend}

\begin{abstract}
As of the global issues in the cultural sector, raises the interest of the community to find out and gather at a point where the culture where can be educated. The global issue regarding cultural trends that had been got from the survey results is the Hallyu Wave, which is the South Korean's Culture wave that is at the peak of nowadays's public discussions in the world. The purpose of this study was to determine the communication patterns developed by all levels of society and to determine the process of social integration that is carried out. Site selection and building planning are also need to pay attention to the originals of South Korea's architectural authenticity, which later must be adapted to the Indonesian environment within a surface called hub. This hub is planned with the contextuality of musical analogies method in its architectural implementations, such as the lows-highs and the fronts-backs applications on its architectural, which can rise the integration characteristic of South Korean's culture in Indonesia, especially in Jl. Taman Kemang, South Jakarta City, where is the one of the many $3^{\text {rd }}$ Place spots in Jakarta Province, and also its adaptations
\end{abstract}

Keywords: culture; hub; south korea; trend

\section{PENDAHULUAN Latar Belakang}

Manusia sebagai makhluk sosial selalu membutuhkan interaksi sosial dengan sesamanya dalam daur hidupnya. Ruang publik telah menjadi latar bagi perkembangan kehidupan publik, baik dalam kegiatan ekonomi, sosial, hiburan, hingga politik. Berlangsungnya kehidupan publik dengan interaksi sosial menjadi salah satu yang sangat bergantung pada keberadaan dan perkembangan ruang publik. 
Minimnya ruang publik sebagai akibat pengembangan yang hanya berorientasi pada kepentingan diri sendiri, mengakibatkan masyarakat mengatasinya secara mandiri. Mereka mengadakan sendiri ruang publik di lingkungan pemukimannya dengan kemungkinan akses yang lebih besar. Sebuah lapangan terbuka di tengah permukiman sering menjadi pusat sosialisasi para warga.

Saat ini, isu berdasarkan hal yang menarik dan sedang trend di kalangan masyarakat Indonesia yaitu mengenai fenomena kebudayaan, yang berasal dari Negara Korea Selatan. Isu mengenai kebudayaan Korea Selatan didapatkan berdasarkan survey wawancara terhadap 100 responden yang telah dilakukan sebelumnya. Dengan studi dan kajian mengenai hubungan isu fenomena kebudayaan yang sedang trend masyarakat Indonesia saat ini dengan third place sebagai ruang sosial, maka diharapkan dengan pengajuan Korean Cultural Phenomenon ini menjadi wadah yang didesain dengan maksud agar mewadahi kebutuhan sosial dan tersier masyarakat. Dengan menggabungkan unsur Hospitality, Entertainment dan Commercial, diharapkan proyek ini dapat menyediakan sarana, prasarana, fasilitas sosial dan fasilitas umum yang bermanfaat bagi keberlangsungan hidup masyarakat umum setingkat kelurahan.

Korea Selatan merupakan salah satu negara yang berada di Asia Timur dengan jumlah penduduk 51,45 Juta Jiwa penduduk pada tahun 2017 serta memiliki pendapatan per kapita yang cukup tinggi yakni US\$33.100 pada tahun 2015. Negara ini telah berkembang menjadi salah satu negara maju dalam bidang teknologi maupun dunia hiburannya terutama dalam penyebaran budaya Korea Selatan di kancah internasional, hal ini biasanya disebut dengan istilah Korean Wave / Hallyu Wave. Korean Wave dapat diartikan sebagai fenomena budaya populer Korea Selatan yang mulai mendunia dan menarik perhatian para peminatnya, yang mana pada umumnya orang-orang akan menyukai musik, fashion, drama, film, makanan, kebudayaan lokal, maupun bahasa Korea Selatan.

Menurut Selo Soemardjan dan Soelaeman Soemardi, kebudayaan merupakan sebuah hasil karya, rasa, cipta manusia. Suatu budaya yang tersebar dapat terjadi apabila budaya tersebut dapat diterima, dipelajari hingga dapat diterapkan dalam kehidupan sehari-hari. Kebudayaan sendiri berarti keseluruhan sistem gagasan, tindakan dan hasil karya manusia dalam rangka kehidupan masyarakat, sebagaimana ini berasal dari kata budhayah yaitu jamak dari buddhi yang berarti "budi" dan "akal" yang dapat diartikan kebudayaan adalah sesuatu yang berhubungan dengan akal. Maka daripada itu dalam usaha penyebaran budaya Korea Selatan yang mampu diterima dan diterapkan masyarakat dalam kesehariannya, merupakan suatu kekuatan yang mampu membuat Korean Wave dapat tersebar dan bertahan hingga sekarang. Perihal hubungan Indonesia-Korea Selatan dalam lingkup sosial budaya telah dimulai pada tahun 2000 yang mana Indonesia meratifikasi kerjasama kedua negara dalam bidang budaya, pariwisata pada tahun 2006, pendidikan pada tahun 2009, industri kreatif pada tahun 2013. Namun hubungan diplomatik antara Indonesia dan Korea Selatan sendiri sudah dimulai sejak tahun 1973, bahkan pada 7 tahun sebelumnya kedua negara ini telah menjalin hubungan konsuler yaitu pada tahun 1966. (Kemenlu.go.id, 2020)

\section{Rumusan Masalah}

Pemilihan isu merupakan hasil dari pertimbangan berbagai aspek permasalahan, antara lain:

a. Kebudayaan mereka yang dapat menyesuaikan dengan perkembangan zaman saat ini.

b. Adanya kecocokan antara budaya Korea Selatan dan Indonesia sehingga adanya hubungan timbal balik dari masing-masing kebudayaan

c. Indonesia merupakan target pasar Korea Selatan yang utama di Asia, bersamaan dengan China, Jepang, dan Thailand. 
d. Perlunya fasilitas untuk masyarakat Indonesia sebagai wadah untuk berkumpul dengan ketertarikan dengan kebudayaan Korea Selatan

e. Diperlukan perancangan sebuah wadah untuk berkumpulnya warga negara asing dari Korea Selatan untuk mengingatkan kembali Kampung Halaman di negara asalnya.

Setelah melakukan riset terhadap isu yang akan diambil, dilakukan juga survey untuk memilih dimana proyek bangunan akan direncanakan. Kriteria karakter kawasan berdasarkan latar belakang isu adalah :

a. Berada pada Zona Perkantoran, Perdagangan dan Jasa

b. Memiliki citra kawasan sebagai daerah yang populer

c. Kawasan yang merupakan tempat berkumpulnya dari segala kalangan dan kategori umur

d. Kawasan yang sudah direncanakan oleh RTRW-nya sebagai pusat $3^{\text {rd }}$ Place

e. Dekat dengan $1^{\text {st }}$ Place dari masyarakat yang memiliki kebudayaan yang bersangkutan

f. Kawasan yang memiliki transportasi publik

g. Memiliki bangunan-bangunan penunjang untuk berdirinya proyek ini.

Beberapa permasalahan yang dihadapi antara lain adalah :

a. Bagaimana cara memperkenalkan third place kepada masyarakat kota agar dapat mewadahi dan memfasilitasi agar dapat memenuhi kebutuhan tersier masyarakat umum?

b. Third place seperti apa yang tepat untuk isu ini?

c. Program apa saja yang akan mewadahi kebutuhan untuk menyelesaikan isu ini ?

Ruang lingkup penulisan ini adalah untuk mengetahui pengaruh dan hubungan antara sikap individualis masyarakat Indonesia akibat kesenjangan sosial dengan kebutuhan third place sebagai ruang sosial, maka diharapkan dengan studi dan kajian ini dapat menjawab kebutuhan sosial bagi masyarakat khususnya dari proyek Hallyu Integrated Hub ini. Kebutuhan sosial masyarakat di dalam third place pada hal ini seperti: kebutuhan ruang, program ruang, program bangunan, interior, serta harapan masyarakat terhadap kebutuhan third place saat ini. Subjek yang menjadi sasaran penulisan dan penelitian ini adalah masyarakat / penduduk Indonesia dan Korea Selatan, yang memiliki latar belakang yang berbeda-beda.

Target yang dicanangkan oleh PBB mengenai Sustainable Development Goals terdapat tiga target sesuai dengan visi misi generasi millenial, diantaranya:

a. Sustainable Cities And Communities

Menyediakan $3^{\text {rd }}$ Place sebagai wadah untuk memenuhi kebutuhan tersier kawasan yang inklusif, terbuka, multi program dan mendukung terciptanya komunitas sosial maupun ekonomi yang baik, serta memberikan ruang terbuka publik bagi masyarakat baik dari dalam dan sekitar kawasan.

b. Masyarakat perlahan-lahan akan yakin untuk menggunakan transportasi umum dengan adanya thirdplaces ini.

c. Good Health And Well - Being

Menyediakan lingkungan hidup yang sehat seperti merencanakan dan merancang lapangan olahraga yang inklusif dan bisa digunakan oleh seluruh masyarakat umum yang aktif dan positif untuk mencapai kehidupan yang sehat dan bermanfaat.

\section{KAJIAN LITERATUR}

\section{Tentang Open Architecture}

Menurut Elizabeth Diller, Arsitektur adalah teknologi. Dan dapat menyatu dengan semua koneksi yang berbeda dalam Sistem Arsitektur - termasuk Politik, Ekonomi, Sosial dan Kondisi Budaya. Jadi Arsitektur adalah Teknologi itu sendiri. 
Menurut Suryono Herlambang S.T.,M.Arch, bahwa Third Place itu adalah Open City yang memiliki tujuan untuk Open Society dan tujuan ini dikembangkan oleh Arsitek dan Urban Designer.

Di dalam konteks Indonesia, makna Third Places adalah Openness

a. "Third Place" Dapat bermain sebagai penguat Sense Komunitas orang

b. "Third Place" bisa dikatakan sebagai "Ruang Keluarga pada Society"

Dikutip dari Larice dan Macdonad pada tahun 2007, pengertian place bukanlah sesuatu yang abstrak atau sekedar berupa konsep, tetapi Place adalah sebuah fenomena kehidupan yang mengandung unsur pengalaman langsung, mempunyai arti dan merupakan sesuatu yang nyata yang didalamnya terdapat aktivitas yang terjadi terus menerus. Keberadaan Place sangatlah penting karena merupakan sumber dari sebuah identitas yang menunjukkan eksistensi individu maupun komunitas, bahkan lebih dari itu, place mempunyai hubungan yang emosional sangat dalam dan psikologi, baik itu seseorang maupun komunitas. Menurut Ray Ouldenburg, The Problem of Place In America, Istilah Third Place adalah istilah yang umum untuk menandakan tempat-tempat publik yang diadakan secara tetap, sukarela, informal untuk kegiatan informal, seperti berkumpul bersama keluarga atau teman.

Keberadaan third place ditujukan sebagai fungsi tersier (pelengkap) dalam aktivitas sehari hari, (Oldenburg, 1999) menurut Oldenburg terdapat beberapa poin penting yang harus ada didalam third place, yaitu:

a. Neutral ground: Pengunjung bebas mengakses tempat tanpa hambatan apapun

b. Leveler (a leveling place): Tidak terikat dengan status sosial.

c. Conversation is the main activity: Pembicaraan yang menyenangkan antar individu

d. Accessibility and accommodation: Dapat memenuhi kebutuhan penggunanya

e. The regulars: Pengunjung lama dapat menarik pengunjung baru

f. A low profile: Tidak mahal dan sederhana

g. The mood is playful: Memiliki sifat yang menyenangkan

h. A home away from home: Spiritual regeneration

\section{Tentang Hub}

Hub merupakan istiliah dari Bahasa Inggris yang berarti sebagai pusat dari aktivitas yang sangat penting dalam hal keberlangsungan aktivitas tersebut, yang dikutip dari kamus Cambridge.Contohnya adalah Jakarta Creative $\mathrm{Hub}(\mathrm{JCH})$ yang ada di Kota Administrasi Jakarta Pusat, Provinsi DKI Jakarta $(\mathrm{JCH})$ mewadahi kegiatan para masyarakat dalam Kota sebagai wadah kreatifitas, baik hanya untuk berkumpul dengan komunitasnya maupun untuk berentrepreneurship.

\section{Tentang Kebudayaan Korea Selatan}

Korea Selatan merupakan negara didalam Benua Asia pada bagian timurnya. Setelah melalui berbagai pergantian masa Kerajaan / Dinasty dan masa penjajahan hingga tahun 1945, Negara Korea dibagi menjadi dua yang dibentuk oleh Uni Soviet dan Amerika Serikat, dan Korea Selatan menjadi negara bentukkan dari Amerika Serikat.

Kebudayaan Korea Selatan memiliki daya tarik budaya yang menjadi sebuah trend saat ini, seperti :

a. Aliran bangunan arsitektural berkonsep Neo-Confuscianism, yang memiliki arti bahwa bangunan yang berasal dari sisi spiritual dari "Buddha" yang diadaptasi dengan perkembangan zaman sehingga memiliki bentuk sederhana / minimalist dan mempermainkan perasaan / psikologi pengguna bangunan tersebut.

b. Memiliki musik aliran Trot (merupakan musik tradisional khas Korea Selatan) dan K-Pop (penggabungan musik Pop, Rock, dan Techno; adaptable terhadap zaman. 


\section{PEMBAHASAN DAN ANALISIS}

\section{Studi Preseden}

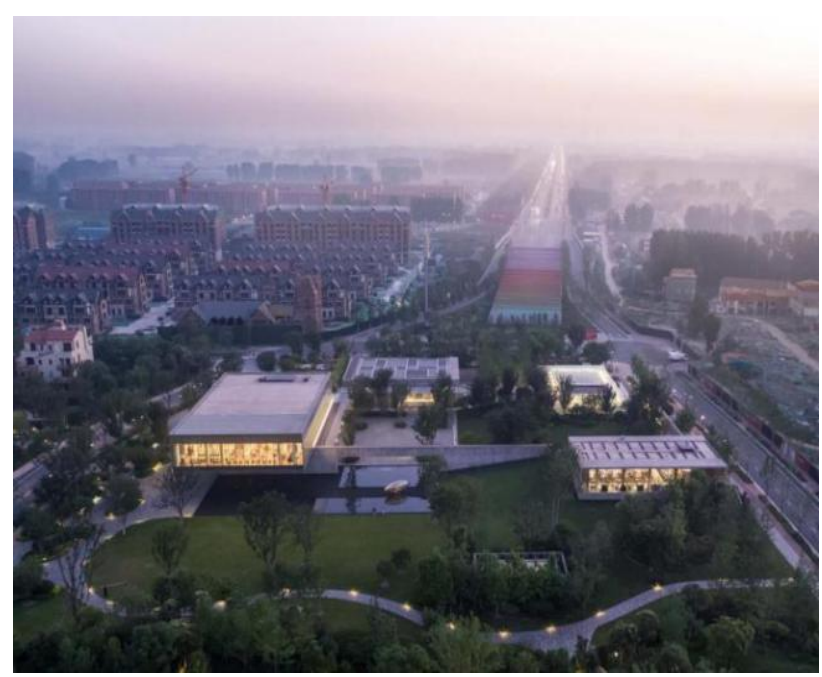

Gambar 1. Ideal Land-Art \& Culture Center, China

Bangunan di atas adalah bangunan publik berkonsepkan 3rd Place sebagai bangunan pelayanan kebudayaan untuk sebuah kawasan hunian, yang berada di Zhengzhou. Memiliki building massing yang terpisah antara fungsi satu sama lain yang masing-masing memiliki fungsi berbeda-beda danmterpisah agar fungsi didalamnya tidak terganggu dengan fungsifungsi bangunan lainnya, dan menjadi kebutuhan ruang hijau kawasan.

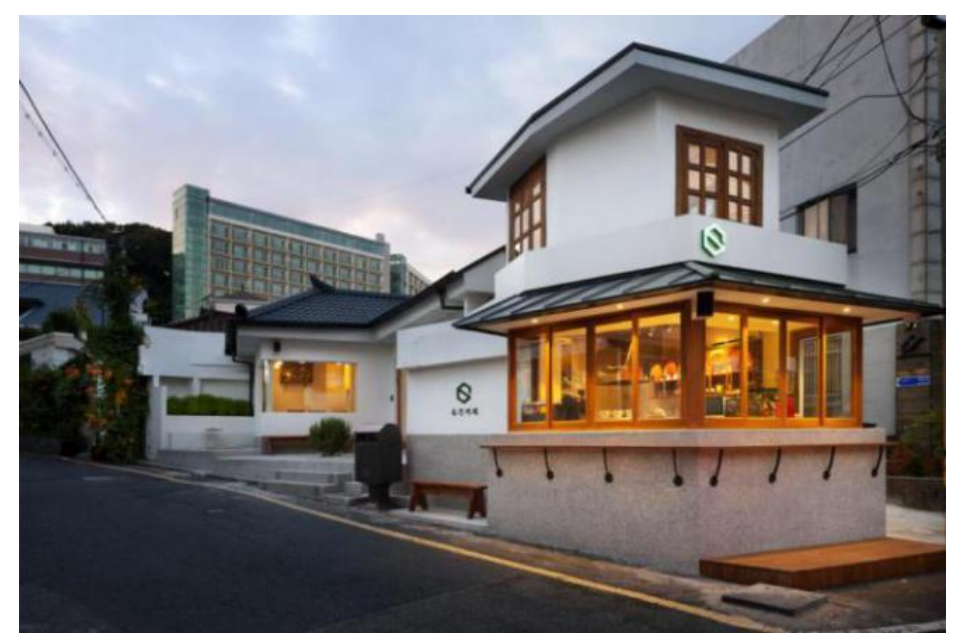

Gambar 2. 6K Coffee, South Korea

Bangunan di atas adalah bangunan publik ( cafe) di daerah Nam-Gu yang kontekstual terhadap arsitektural khas Korea Selatan. Permainan interior menjadikan kondisi arsitektural bangunan bergaya International Styles, yang mengikuti perkembagan zaman. 


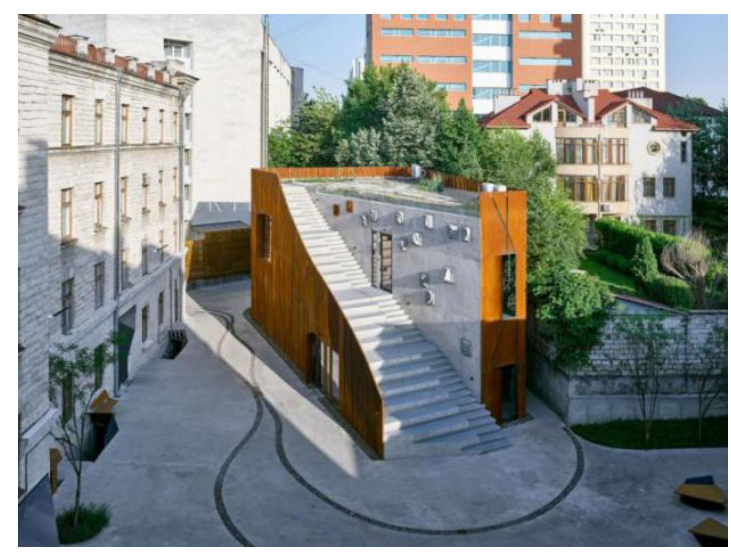

Gambar 3. ARTCOR Creative Centre, Moldova

Bangunan ini menjadi bangunan "penerima', dan icon dari kawasan Chisnau, dan memiliki elevated entrance untuk masuk kedalam bangunannya, yang implementasinya dengan tangga luar yang langsung menuju ke rooftop bangunan ini.

\section{Analisis Program}

Dalam pemrograman dari bangunan proyek Hallyu Integrated Hub ini mengadaptasi dari program bangunan di kawasan Jl. Taman Kemang yang terdiri atas entertainment, hospitality, dan commercial. Ketiga konsep ini menjadi wadah dari studi, survey, dan analisis yang telah diusulkan menggunakan Bubble Diagram dari buku Transformasi Desain, sehingga terbentuk pola pola ruang, baik ruang dalam maupun ruang luar bangunan untuk perancangan bangunan nantinya.

Tabel 1. Programming dan luasan ruang dalam bangunan proyek

\begin{tabular}{|c|c|c|c|}
\hline Proyek & Program & Program Arsitektur & Luasan \\
\hline \multirow{13}{*}{$\begin{array}{c}\text { Korean } \\
\text { Integrated } \\
\text { Hub }\end{array}$} & \multirow{4}{*}{ Hospitality } & Performing Arts Studio & $400 \mathrm{~m} 2$ \\
\hline & & Study Hall & $100 \mathrm{~m} 2$ \\
\hline & & Library & $150 \mathrm{~m} 2$ \\
\hline & & Cultural Plaza & $1000 \mathrm{~m} 2$ \\
\hline & \multirow{4}{*}{ Entertainment } & Gallery / Exhibition Hall & $400 \mathrm{~m} 2$ \\
\hline & & Mini Concert Hall & $1000 \mathrm{~m} 2$ \\
\hline & & Theatre & $500 \mathrm{~m} 2$ \\
\hline & & Dance Studio & $100 \mathrm{~m} 2$ \\
\hline & \multirow{5}{*}{ Commercial } & BBQ Restaurant & $300 \mathrm{~m} 2$ \\
\hline & & Cafe & $200 \mathrm{~m} 2$ \\
\hline & & Souvenir Shop & $100 \mathrm{~m} 2$ \\
\hline & & Culinary Experiences & $500 \mathrm{~m} 2$ \\
\hline & & Online Driver Area & $50 \mathrm{~m} 2$ \\
\hline
\end{tabular}

Sumber: Dokumen Pribadi, 2020 


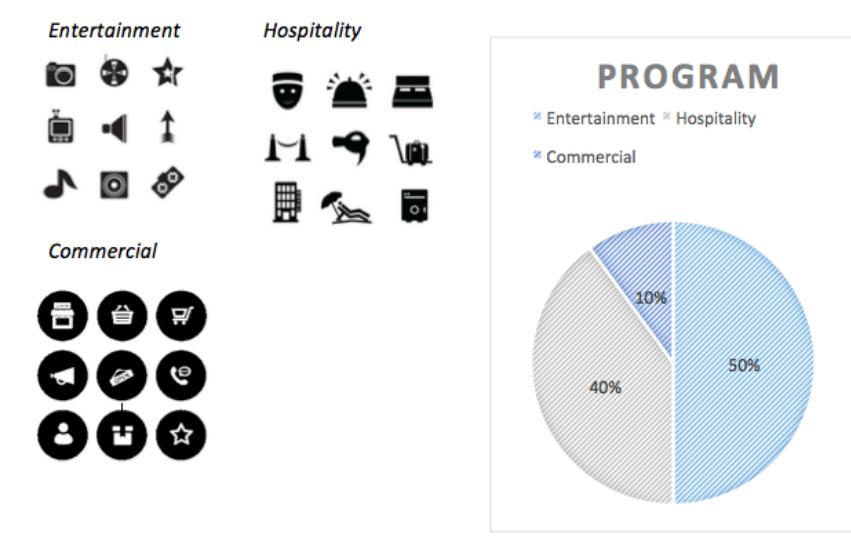

Gambar 4. Representasi dan persentase programming bangunan proyek Sumber: Dokumen Pribadi, 2020

Konsep perancangan yang dimaksud adalah :

a. Konsep bangunan publik Korea Selatan adalah Sport Architecture, yang berarti setiap bangunan publiknya harus memiliki ruangan yang luas untuk para pengguna di dalamnya berinteraksi satu sama lain.

b. Menentukan pola bangunan dengan grid system

c. Mewujudkan bangunan dengan International Styles; memiliki wujud yang mengikuti perkembangan zaman

d. Penerapan elemen berbatuan pada beberapa bagian bangunannya

Perancangan ruang luar dimaksimalkan dengan landscaping yang terinspirasi dari beberapa icon pariwisata di Korea Selatan, dan juga pemanfaatan GSB (garis sepadan bangunan) yang dimanfaatkan sebagai sirkulasi yang mengelilingi bangunan proyek.
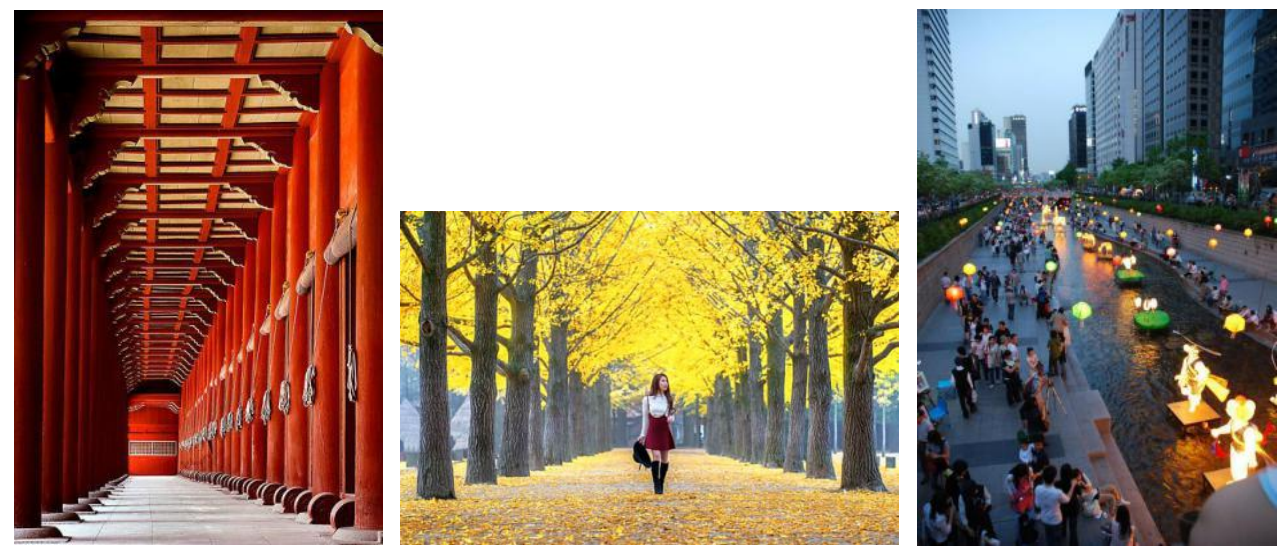

Gambar 5. Konsep Perancangan Proyek

Pada konsep bangunan proyek ini memiliki konsep Kontekstual terhadap lingkungan site ( Respond to Site ) yaitu daerah JI. Taman Kemang, yang nantinya dikorelasikan dengan konsep bangunan dari sisi arsitektural khas Korea Selatan

\section{Analisis Tapak}

Tapak terpilih berada di Jl. Taman Kemang, Kelurahan Bangka, Kota Administrasi Jakarta Barat, yang merupakan area memiliki karakter $3^{\text {rd }}$ Place yang kuat sesuai dengan teori Ray Oddinburg, serta berada di dekat dengan hunian Warga Negara Asing asal Korea Selatan pada sisi Barat ( area Dharmawangsa dan area Blok A) dan Apartemen Kemang Village. 


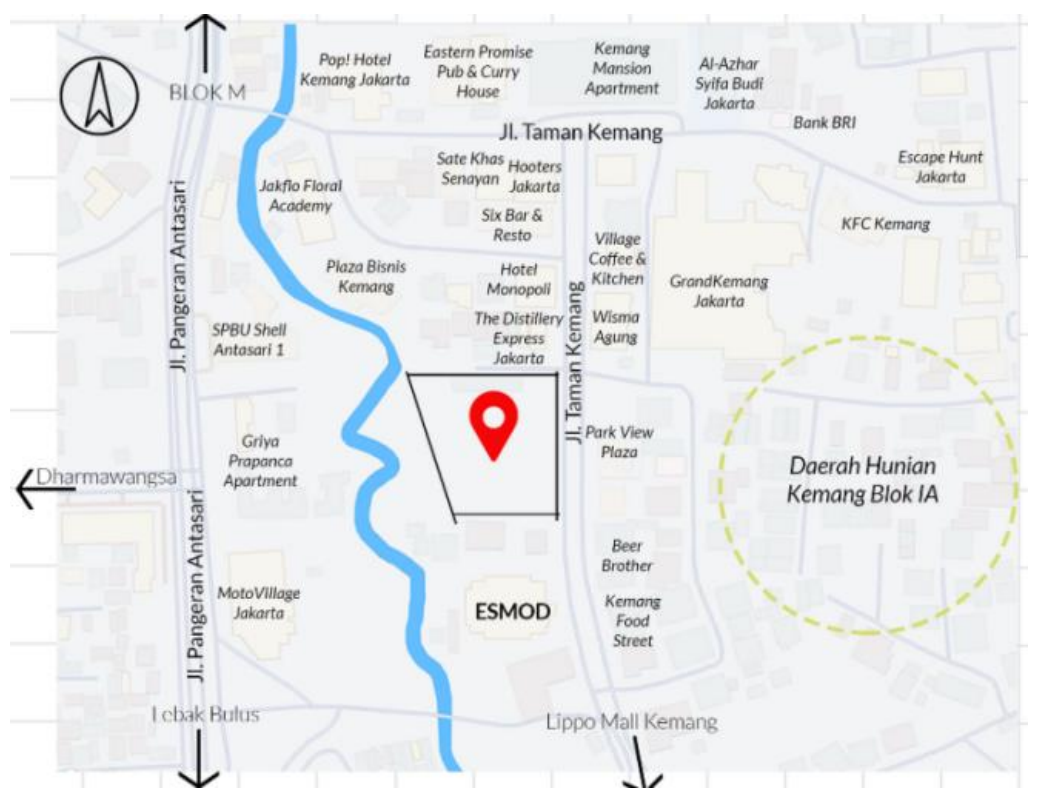

Gambar 6 . Lokasi site proyek

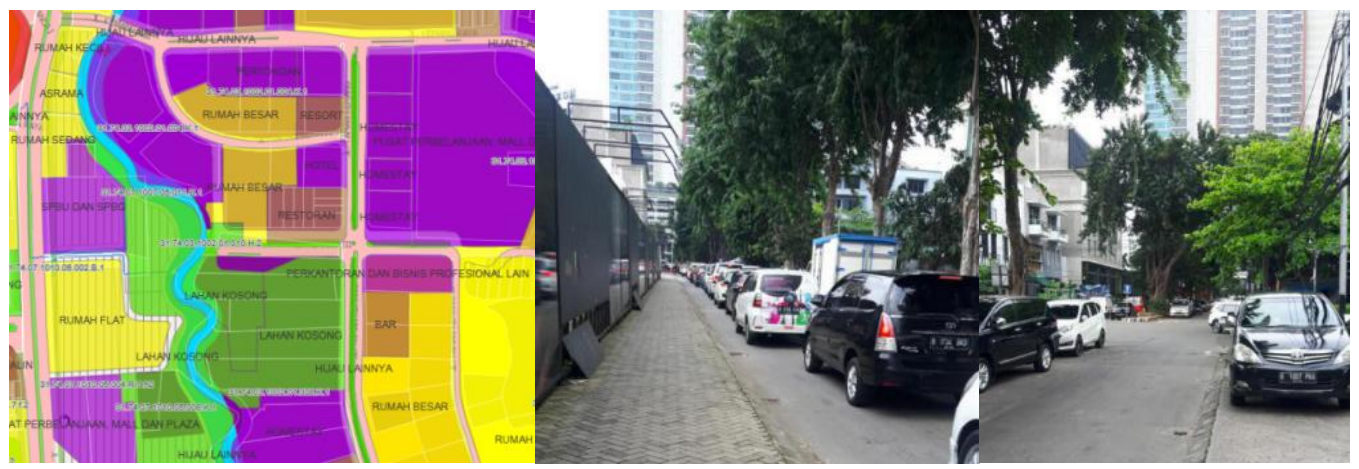

Gambar 7. Tata guna lahan, dan kondisi existing site

Tabel 2. Persentase tata guna lahan dan penggunaan lahan bangunan proyek

\begin{tabular}{|c|c|c|}
\hline No. & Keterangan & Data \\
\hline 1. & KDB & $50 \%$ \\
\hline 2. & KLB & 2 \\
\hline 3. & KB & 4 \\
\hline 4. & $\mathrm{KDH}$ & $35 \%$ \\
\hline 5. & KTB & $55 \%$ \\
\hline 6. & TIPE & $\mathrm{T}$ \\
\hline 7. & PSL & KP \\
\hline 8. & Luas Tapak & $7,000 \mathrm{~m}^{2}$ \\
\hline 9. & Luas keseluruhan yang terbangun & $5,000 \mathrm{~m}^{2}$ \\
\hline 10. & Luas daerah hijau & $2,450 \mathrm{~m}^{2}$ \\
\hline 11. & Luas lantai dasar & $2,500 \mathrm{~m}^{2}$ \\
\hline
\end{tabular}

Sumber: Dokumen Pribadi, 2020 


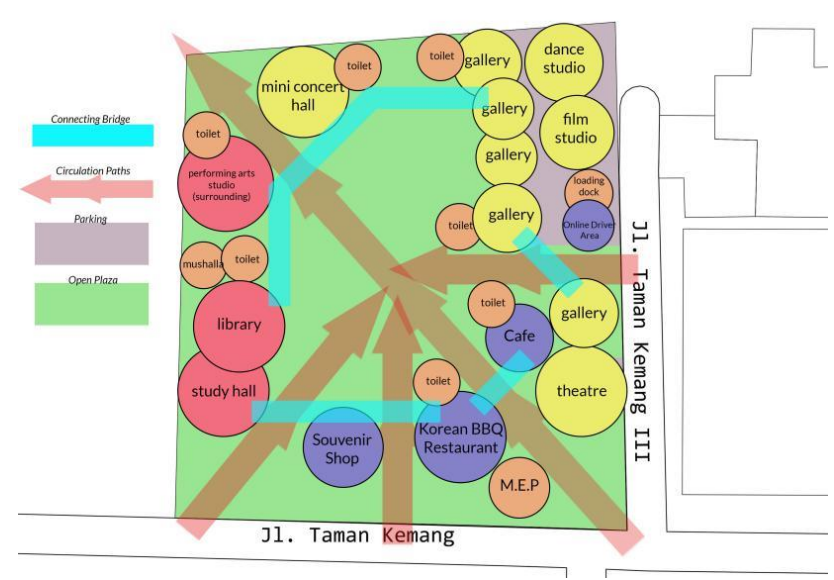

Gambar 8. Bubble Programming program bangunan proyek sebagai langkah awal perancangan proyek

Sumber: Dokumen Pribadi, 2020

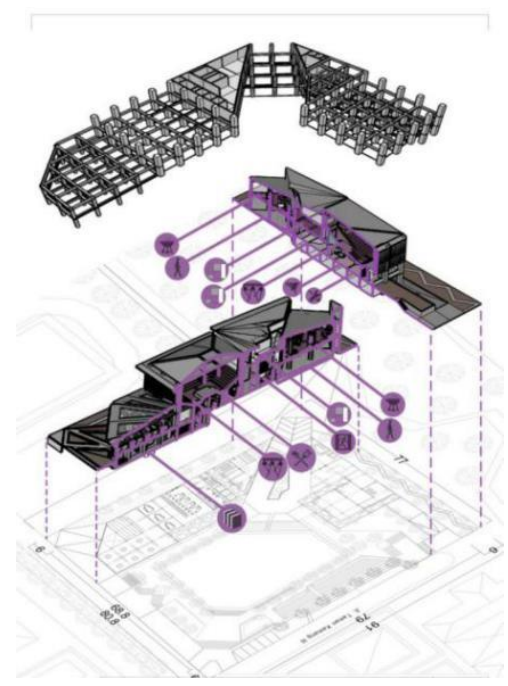

Gambar 9. Pembagian Program Ruang Bangunan Proyek Sumber: Dokumen Pribadi, 2020

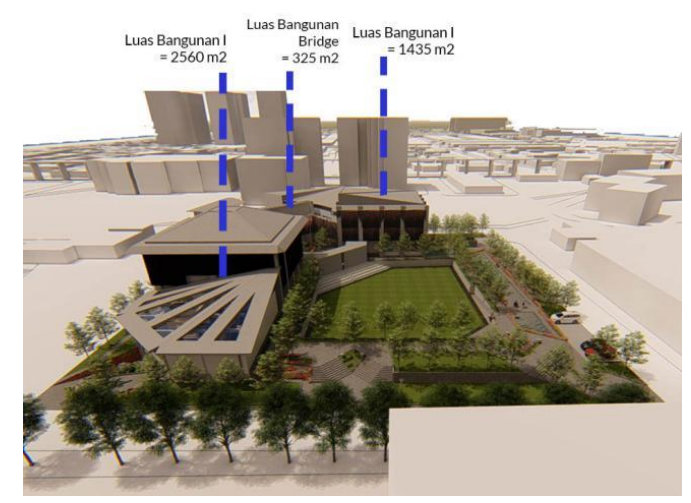

Gambar 10. Perspektif depan dan luasan dari dalam Bangunan Proyek Sumber: Dokumen Pribadi, 2020 


\section{DISKUSI DAN HASIL}

Pada konsep bangunan proyek ini memiliki konsep Kontekstual terhadap lingkungan site (Respond to Site ) yaitu daerah Jl. Taman Kemang, yang nantinya dikorelasikan dengan konsep bangunan dari sisi arsitektural khas Korea Selatan.
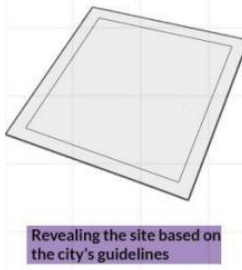

Menetapkan garis batas lahan proyek dan mengikuti peraturan
TPZ yang telah diatur oleh Tata TPZ yang telah
Kota setempat.
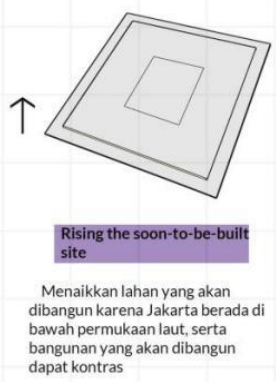
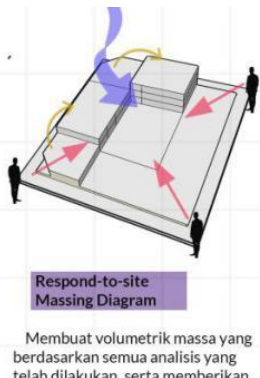
berdasarkan semua analisis yang
telah dilakukan, serta memberikan irama pada massa bangunan.
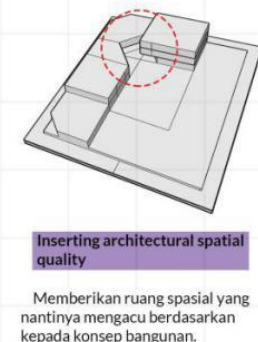

nantinya mengacu berdasarkan

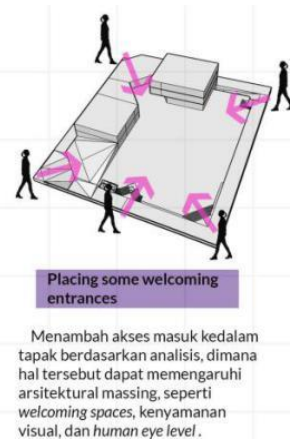

Gambar 11 : Proses gubah massa bangunan proyek Sumber: Dokumen Pribadi, 2020

Setelah penyesuaian bangunan terhadap lingkungan site, impelementasi integrasi antara dua kebudayaan berbeda, yaitu Kebudayaan Korea Selatan di Indonesia, diperlukan sebuah wadah untuk memperkenalkan dan mengedukasi yang telah dirancang didalam bangunan, baik berupa ruang interaksi, sirkulasi, maupun ruang pertunjukkan.

Perkenalan budaya yang paling mudah adalah melalui makanan. Dengan program Culinary Experiences di dalam bangunan proyek dapat menjadi salah satu daya tarik proyek ini. Terdapat sebuah Food Bar dan Culinary Kitchen didalamnya. Keduanya memiliki fungsi sama dan praktik yang berbeda, yaitu pada Food Bar dapat dilayani oleh pramusaji / food vendor, sedangkan pada ruang Culinary Kitchen pengguna dapat memiliki pengalaman dapat membuat makanan sendiri.

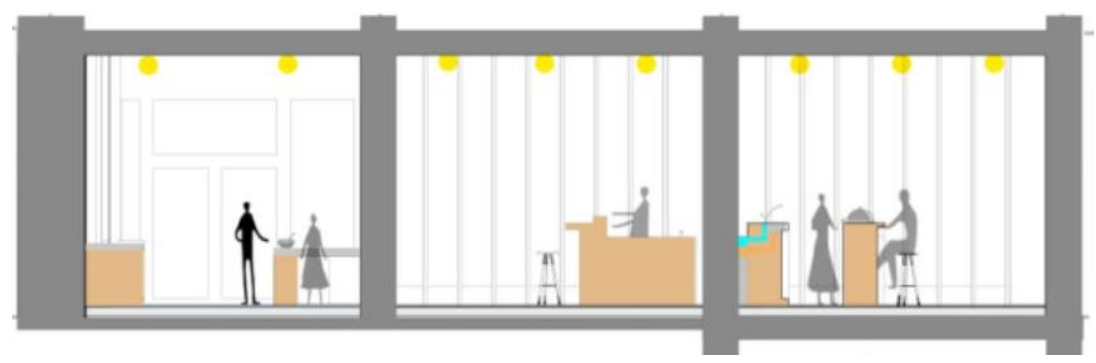

Gambar 12. Ilustrasi program Culinary Experience di dalam bangunan proyek Sumber: Dokumen Pribadi, 2020

Pemanfaatan ruang luar dapat dialihfungsikan sewaktu-waktu, contohnya ruang luar Central Plaza pada tengah tapak dapat digunakan sebagai arena pertunjukkan maupun ruang komunitas, dengan pengalaman perspektif yang berbeda dari plaza itu sendiri maupun dari walkways yang berada di sisi-sisinya.

\section{KESIMPULAN}

Berdasarkan seluruh hasil Studio Perancangan Akhir ini, bangunan proyek ini memiliki landasan utama yaitu trend, dan karakter integrasi yang muncul secara terencana dari hasil analisis dan studi yang sudah dilakukan, dapat mewujudkan satu aspek lagi dari konsep $3^{\text {rd }}$ Place yaitu The Regulars, yang dapat diartikan sebagai pengunjung tetap yang kemunculannya ada ketika bangunan tersebut dibangun, dan menambahkan karakteristik tersendiri pada bangunan 
tersebut. The Regulars yang dimaksudkan adalah warga Negara Asing yang berasal dari Korea Selatan; Representatives dan Aktivitas Kebudayaan Korea Selatan; Masyarakat Indonesia yang memiliki ketertarikan dengan kebudayaan Korea Selatan; Para Budayawan. Dalam keberlangsungannya, dengan adanya regulasi kerjasama mengenai Ekonomi, Sosial, Budaya, Militer, Pendidikan, Imigrasi, dan Politik antara Korea Selatan dan Indonesia yang sudah disahkan sejak September 1973, dan trend kebudayaan Korea yang sedang berada dipuncak, maka keberlangsungan aktivitas didalam proyek akan berlangsung dalam waktu yang lama.

\section{REFERENSI}

A History of Korean Architecture. In order to make an original of Korean Architecture, diakses tanggal 31 Maret 2020, https://brewminate.com/a-history-of-korean-architecture/

Anonim, diakses 12 Februari 2020, https://docplayer.info/44245804-August-comte-selosoemardjan-soelaeman-soemardi.html

Archdaily, diakses 9 Februari 2020, https://www.archdaily.com/929740/baoan-culturalcomplex-rocco-design-architects-associates

Archdaily, diakses 9 Februari 2020, https://www.archdaily.com/930196/6k-coffee-limtaeheedesign-studio

Archdaily, diakses 9 Februari 2020, https://www.archdaily.com/923022/ideal-land-art-andculture-center-verse-design

Archdaily, diakses 14 Februari 2020, https://www.archdaily.com/921208/artcor-creativecenter-maxim-calujac?ad_source=search\&ad_medium=search_result_projects

Hub. Meaning by Oxford Dictionary, diakses 20 April 2020, https://dictionary.cambridge.org/dictionary/english/hub,

Jakarta Creative Hub. Implementasi Hub pada penggunaannya, diakses 20 April 2020, https://crafters.getcraft.com/id-articles/jakarta-creative-hub-wadah-kreativitas

Jiwangga. Kebutuhan Ruang Ketiga, diakses 19 Januari 2020, http://jiwangga.com/MyPad/Entries/2005/9/2_Kebutuhan_Ruang_Ketiga.html/

Jormakka, K. (2008). Basic Design Methods. Switzerland: Birkhäuser Architecture; 1 edition.

Korean Architecture, diakses tanggal 31 Maret 2020, https://www.britannica.com/art/Koreanarchitecture.

Oldenburg, R. (1999). The Great Good Place: Cafés, Coffee Shops, Bookstores, Bars, Hair Salons, and Other Hangouts at the Heart of a Community. United States: Marlowe.

Penataan Ruang, Rencana Tata Ruang Wilayah, diakses 30 Januari 2020, https://jakartasatu.jakarta.go.id/portal/apps/webappviewer/index.html?id=ee9940006aa e4a268716c11abf64565b/

Rencata Tata Ruang Wilayah Jakarta, diakses 10 Februari 2020, https://jakartasatu.jakarta.go.id/portal/apps/webappviewer/index.html?id=ee9940006aa e4a268716c11abf64565b

Sustainable Development Goals. The Sustainable Development Goals, diakses tanggal 19 Januari 2020, https://www.un.org/sustainabledevelopment/sustainable-developmentgoals/

Third Place, diakses 19 Januari 2019, https://www.101thethirdplace.com/

Website resmi Kementrian Luar Negeri Republik Indonesia, diakses 20 Januari 2020, https://kemlu.go.id/seoul/id/pages/hubungan_bilateral/558/etc-menu 
